\title{
Evolution Towards the Implementation of Point-Of-Care Biosensors
}

\author{
Veronique Vermeeren and Luc Michiels \\ Hasselt University \\ Belgium
}

\section{Introduction}

Health care, food quality control, and environmental management often rely on the detection of abnormal molecules, in the body, in food, and in the environment, respectively. More and more, these fields are moving towards point-of-care detection, since increased analysis speed, and hence, decreased cost, are becoming important determining factors for funding.

In parallel, but also to allow for this speedy and on-site analysis, the scientific world has evolved into the 'nano'-scale. This was made possible by the dawn of bio-electronics: a scientific field coupling the achievements in molecular biology with the advances in electronics. The goal of this field is to interrogate the functional activity of bioreceptor molecules, i.e. the recognition and/or metabolization of their targets, with electronics to increase the detection speed for, and sensitivity to, certain pathogens, pollutants, and genetic mutations.

To enable the electronic interrogation of these bioreceptor molecules, they need to be attached to, or embedded into, a solid support or transducer with a favourable orientation and density, ensuring the retention of their biological functionality. The resulting analytical device is called a biosensor. The transducer 'translates' the biological recognition event between the receptor molecule and its target into a readable signal.

Many biosensors have become established in the clinical and scientific world. However, still few of them have made it to point-of-care applications. The success and applicability of biosensors as point-of-care tools is based on five requirements. They need to be sensitive, specific, fast, cheap, and portable. Electronic biosensors based on (semi-)conductive transducers are hence preferred for point-of-care applications, since they are fast in signal generation and cheap to produce.

Many popular semiconductive transduction materials, such as silicon (Si) and germanium (Ge), however, are susceptible to hydrolysis, leading to a loss of bioreceptor molecules from the surface, and hence, to instability of the sensor platform. This negatively influences the sensitivity and specificity of the sensor. This explains our increased attention towards diamond, which surpasses $\mathrm{Si}$ and Ge on many levels. It can be made into a semiconductor, preferred for electronic applications, it is chemically and mechanically very stable, it can be functionalized with bioreceptor molecules (DNA, aptamers, antibodies, whole cells), and it is biocompatible since it is only composed of carbon (C). 
For this reason, this contribution will focus on the application of diamond in the construction of different types of electronic biosensors to be used in clinical diagnostics, food industry and environmental management.

\section{Biosensor types and their application areas}

\subsection{DNA-sensor}

A DNA-sensor is constructed by immobilizing a single-stranded DNA (ssDNA) molecule with a sequence corresponding to (a part of) the gene of interest to a solid substrate. Hybridization with a perfectly complementary sequence present in the sample will lead to a specific signal.

\subsubsection{Clinical diagnostics}

The DNA contains the blueprint of the human body. The genes that encode our proteins make up our phenotype. However, when mutations occur in these genes, this could lead to the formation of aberrant or non-functional proteins, infringing on the normal function of the human body. Diseases, such as cancer, sickle cell anemia, Charcot Marie Tooth's disease, Duchenne's muscular dystrophy, and many more, are caused by such DNA mutations. Detection of these mutations in the DNA is therefore paramount for the correct diagnosis and therapeutic intervention.

A well-known application of a DNA-sensor principle is the microarray. In oligonucleotide microarrays, short genomic ssDNA fragments are spotted on the microarray, and all of the sequences on the array can cover an entire genome. Oligonucleotide microarrays are therefore mainly used for extensive genetic profiling and mutational analysis. The arrays are hybridized with fluorescently labeled genomic DNA and evaluated with a fluorescence microscope equipped with a CCD camera. These microarrays yield absolute values of the presence or absence of each particular gene sequence on the array and therefore, the comparison of two conditions, such as a healthy control and a cancerous patient, requires the use of two separate microarrays for the parallel genotyping or mutation analysis of multiple genes.

In cDNA microarrays, entire cDNA molecules are spotted on the microarray, and all of the sequences can cover the expressional activity of a certain cell or tissue type. cDNA microarrays are therefore mainly used for gene expression analysis. To compare two conditions, such as the gene expression level in a certain tissue of a healthy control and gene expression level in a certain tissue of a cancerous patient, mRNA is isolated from the tissue of the healthy control and from the tissue of the cancerous patient. Both mRNA sources are labeled with a different fluorescent dye, and the array is hybridized with a mixture of both mRNA sources. The fluorescence is again evaluated with a fluorescence microscope. These microarrays compare the expression level of the two conditions for each particular gene on the array. Hence, one microarray can be used for the expression analysis of two conditions.

However, the requirement of target labeling, and the associated need for very expensive complex optics for detection, make microarrays an extremely costly investment. For this reason, focus has shifted towards electronic, label-free DNA-sensors. DNA-based biosensors have been reported that exploit the intrinsic electro-activity of the bases guanine $(G)$ and adenine (A). Probe ssDNA is attached to the electrode surface, and the $G$ and/or A residues in the DNA participate in a redox reaction. The current that is generated during this redox 
reaction is detected, and it is proportional to the amount of $\mathrm{G}$ and/or $\mathrm{A}$, being larger in double-stranded DNA (dsDNA). However, usually, direct detection of the G and/or A bases without the use of redox mediators is generally considered to be too insensitive. Cai et al. (2004) immobilized ssDNA onto Si electrodes, and demonstrated that they were able to distinguish complementary DNA from DNA containing 4-base mismatches as compared to the immobilized probe DNA (Cai et al., 2004). Gu et al. (2005) and Vermeeren et al. (2007) even succeeded in single-nucleotide polymorphism (SNP) sensitivity, the latter in real-time (Gu et al., 2005), (Vermeeren et al., 2007).

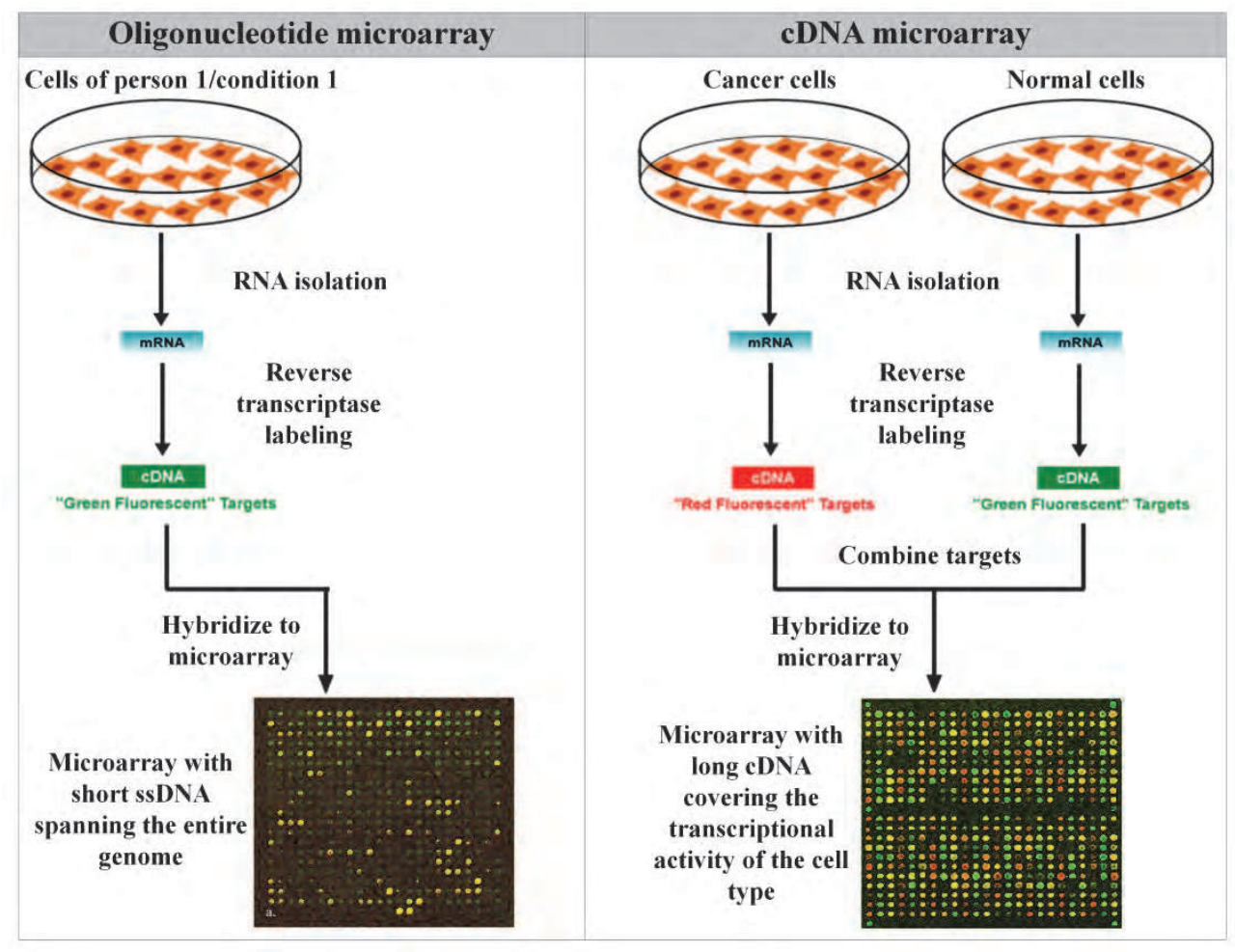

Fig. 1. Schematic diagram of an oligonucleotide microarray (left panel) and a cDNA microarray (right panel). An oligonucleotide microarray, modified with short oligonucleotide sequences covering the entire genome, gives information about the presence and absence of certain gene fragments. Each microarray is hybridized with target material of 1 condition. A cDNA microarray, modified with longer cDNA sequences covering the expressional activity of a cell type, are used for gene expression analysis. Each microarray is hybridized with target material of 2 conditions.

\subsubsection{Food industry}

The use of genetically modified strains of crops is becoming more and more widespread. Informing the consumers is of utmost importance. Moreover, the presence of contaminating 
microbial life in food and is a major health care concern. Therefore, biosensor research has focused on the detection of genetically modified organisms (GMOs) and viral and the presence of viral or bacterial DNA in food.

Tichoniuk et al. (2008) developed an electrochemical DNA-sensor that was capable of distinguishing between genetically modified and unmodified soybeans without DNA amplification. Gold $(\mathrm{Au})$ electrodes were modified with ssDNA corresponding to genetically modified soybeans. Methylene blue was used as a hybridization indicator, interacting more readily with $G$ in ssDNA than in dsDNA. Hybridization with modified soybeans was reflected by a decrease in the voltammetric peak of methylene blue, while treatment with unmodified soybeans had no effect in the peak (Tichoniuk et al., 2008). JoonHyung et al. (2008) constructed a label-free electrochemical DNA-sensor against Salmonella. Salmonella species are classified as bioterrorism threat agents by the Center for Disease Control and prevention (CDC). DNA from Salmonella Enterica Serovar Enteritidis was amplified by Polymerase Chain Reaction (PCR) and exposed to a nanoporous Si substrate modified with Salmonella-specific 26-mer probe ssDNA (Joon-Hyung et al., 2008).

\subsubsection{Environmental management}

DNA-sensors are also starting to be used to screen various environmental matrices, such as water, soil, and plant samples, for the presence of infectious agents and analytes that have binding affinities for the structure of DNA, and thus induce DNA damage.

Marrazza et al. (1999) developed two disposable electrochemical DNA-sensors, one based on DNA hybridization to detect the presence of the bacteria Chlamydia trachomatis, and one based on the interaction of small molecules with the DNA. For the first sensor, 21-mer ssDNA probes specific for Chlamydia were immobilized onto a graphite screen-printed electrode. Potentiometric Stripping Analysis (PSA) was used to detect the hybridization to complementary target DNA. The increasing oxidation peak area of daunomycin, an intercalator of dsDNA, was used as an indicator for the hybridization, and thus for the presence of Chlamydia in the sample. However, the sensitivity of the assay was insufficient to allow a direct detection without PCR amplification of the sample. Their second sensor was constructed by immobilizing calf thymus ssDNA onto a graphite screen-printed electrode. The decreasing oxidation peak of $G$ was used as an indicator for the interaction between ssDNA and cisplatin and polychlorobiphenyls (PCBs). They even tested real river water samples, and succeeded in the rough categorization into toxic and non-toxic water samples. However, they were not able to distinguish between the different compounds that were present (Marrazza et al., 1999).

\subsection{Immunosensor}

An immunosensor is constructed by immobilizing an antibody directed against the protein target of interest to a solid support. Recognition of its target antigen will lead to a specific signal.

\subsubsection{Clinical diagnostics}

Since many diseases have their origin in the presence of DNA mutations in crucial genes, as explained above, these diseases are also often characterized by the presence of abnormal proteins in the body. Diagnosis is based on the detection and quantification of these proteins by using antibodies directed against the protein of interest. The state-of-the-art is the Enzyme-Linked ImmunoSorbent Assay (ELISA). There are three types of ELISA. 
In a sandwich ELISA, the ELISA plate is coated with target-specific antibodies. In a next step, the sample is added, and the antigens, if present, will bind to the coated antibodies. In a third step, detection antibodies, labeled with an enzyme, will bind to a different epitope of the bound antigens. Lastly, the substrate of the enzyme label is added, which is metabolized into a colored product of which the absorption is measured. The absorption is then directly proportional to the amount of bound target.

In an indirect ELISA, the sample containing or not containing the target of interest is coated onto the ELISA plate. In the next steps, the enzymatically labeled detection antibodies and the substrate are added like in the sandwich ELISA, and the absorption is again a measure for the bound targets.

In a competitive ELISA, the enzymatically labeled detection antibodies are first preincubated with the target antigens. Only the detection antibodies that are still free after this pre-incubation step will be available to bind to target antigens that are coated onto the ELISA plate. Here, the absorption of the enzymatically generated product is indirectly proportional to the amount of target antigen in the sample.

Many ELISA kits exist for all sorts of applications. However, the technique requires many reaction steps, which increases the analysis time and cost. For this reason, focus has shifted towards electronic, label-free immunosensors. Fang et al. (2010) described the development of a novel immunosensor based on a sol-gel derived Barium Strontium Titanate (BST) thin film and interdigitated electrodes for the diagnosis of Dengue infection. The Dengue virus particles were immobilized onto the electrodes, to capture the Dengue antibodies present in human serum. With impedance spectroscopy and I-V measurements, it was possible to detect Dengue antibodies in human serum even after a 50 000-fold dilution. Since Dengue infection is also diagnosed using the salivary antibodies, of which the concentration is relatively close to the concentration in serum, the sensor could possibly be employed in an easy, rapid point-of-care setting (Fang et al., 2010). Pan et al. (2010) developed an amperometric immunosensor for the diagnosis of Urinary Tract Infection (UTI), using lactoferrin (LTF) as a biomarker for UTI. They immobilized biotinylated anti-LTF onto Au electrodes functionalized with self-assembled monolayers (SAMs) coupled with biotin and strepatvidin. Detection was based on a horse-radish peroxidise (HRP)-conjugated anti-LTF antibody and the HRP substrate. The current generated by the enzymatic reaction was transferred to the electrodes through the use of the redox mediator potassium ferricyanide $\left(\mathrm{K}_{3} \mathrm{Fe}(\mathrm{CN})_{6}\right)$. They reached a detection limit of $145 \mathrm{pg} / \mathrm{ml}$ (Pan et al., 2010).

\subsubsection{Food industry}

Electrochemical immunosensors can also be applied in food analysis, for quality control. For example, Chemburu et al. (2005) developed a flow-through amperometric immunosensor to detect the presence of E. coli, L. monocytogenes, and C. jejuni. They immobilized antigenspecific antibodies onto carbon particles, and obtained detection limits of 50, 10, and 50 colony-forming units $(\mathrm{CFU}) / \mathrm{ml}$, respectively. They then applied this to milk and chicken extract, and observed a L. monocytogenes detection limit of $30 \mathrm{CFU} / \mathrm{ml}$ in chicken extract (Chemburu et al., 2005). Micheli et al. (2004) constructed an electrochemical immunosensor against domoic acid. Domoic acid is a neuroexcitatory toxin from marine diatoms, found in sea products. It is the causative agent of amnesic shellfish poisoning (ASP). Using screenprinted electrodes, the authors claim a detection limit of domoic acid of $20 \mu \mathrm{g} / \mathrm{g}$ in mussels, which is the maximum acceptable limit defined by the Food and Drug Administration (FDA) (Micheli et al., 2004). 


\subsubsection{Environmental management}

Pesticides are widely used in agriculture to protect crops. However, their use has also created serious concerns regarding their effects on the environment. Hence, identification and quantification of pesticides is of utmost importance. Skládal and Kaláb (1995) developed a multichannel amperometric immunosensor for the detection of 2,4dichlorophenoxyacetic acid (2,4-D). They used a competitive format. 2,4-D molecules conjugated with HRP competed with free 2,4-D for the anti-2,4-D antibodies immobilized onto the nitrocellulose-covered Au electrode. The substrate hydrogen peroxide $\left(\mathrm{H}_{2} \mathrm{O}_{2}\right)$ and hydroquinone participated in the redox reaction catalyzed by HRP, and the generated current was detected amperometrically. They achieved a detection limit of $0.1 \mathrm{ng} / \mathrm{ml}$ in water (Skládal et al., 1995). Grennan et al. (2003) described an amperometric immunosensor for the analysis of the herbicide atrazine. The European Union Drinking Water Directive set official regulations on the maximum admissible concentration of atrazine in drinking water, namely $0.1 \mathrm{ng} / \mathrm{ml}$. Single-chain antibodies against atrazine were immobilized in a polyaniline (PANI)/polyvinyl sulfonate (PVS) polymer layer on top of a carbon paste screen-printed electrode. Again, competition between HRP-labeled atrazine and native atrazine ensued, and the subsequent substrate reaction with $\mathrm{H}_{2} \mathrm{O}_{2}$ gave a detection limit of $0.1 \mathrm{ng} / \mathrm{ml}$ (Grennan et al., 2003).

\subsection{Aptasensor}

A recent new development in affinity sensing comes from aptamer molecules. Aptamers are short, synthetic ssDNA or ssRNA oligomers that obtain a specific and complex 3D structure. For this reason, they are able to bind to and recognize a certain target molecule (proteins, organic molecules, cells, ...) with a high specificity. Because of their ease in selection and synthesis, and hence, their cheaper production cost, and their chemical stability in a variety of conditions, they display a great advantage compared to antibodies. For this reason, like antibodies, aptamers are becoming more and more valuable as receptor molecules in biosensors.

\subsubsection{Clinical diagnostics}

Yuan et al. (2010) developed a label-free electrochemical aptasensor for the detection of thrombin. Thrombin is a blood-clotting protein, and a high level of thrombin will cause thrombosis, while a low level will induce excessive bleeding. Nafion-coated Au electrodes were modified with alternating layers of the redox mediator thionine and Au nanoparticles. Thiol (SH)-modified thrombin aptamers were then immobilized onto the Au nanoparticles. The redox peak of thionine was monitored in the presence of $\mathrm{K}_{3}\left[\mathrm{Fe}(\mathrm{CN})_{6}\right] / \mathrm{K}_{4}\left[\mathrm{Fe}(\mathrm{CN})_{6}\right]$. Binding with thrombin resulted in a barrier for the electron transfer to the electrode coming from the redox reaction of thionine, leading to a decrease in current and in the thionine redox peak. When exposing the sensor to human serum samples, they obtained good recovery values with thrombin concentrations between 1 and $40 \mathrm{nM}$ (Yuan et al., 2010).

\subsubsection{Food industry}

Bonel et al. (2010) reported an electrochemical aptasensor for the detection of ochratoxin A (OTA). OTA is one of the most important mycotoxin contaminants of food, particularly cereal grains, such as wheat and their derived products. The presence of OTA in these foods is a matter of great concern, as it is responsible for chronic diseases in humans and animals. 
Biotinylated OTA aptamers were immobilized onto streptavidin-coated paramagnetic beads. Free OTA was allowed to compete with OTA-HRP conjugates for the aptamerfunctionalized beads, and after the magnetic separation, the reacted beads were transferred to screen-printed carbon electrodes. $\mathrm{H}_{2} \mathrm{O}_{2}$ and hydroquinone participated in a redox reaction catalyzed by $\mathrm{HRP}$, and the current was detected amperometrically. They reached a detection limit of $0.07 \mathrm{ng} / \mathrm{ml}$, and the sensor was accurately applied to certified wheat samples (Bonel et al., 2010).

\subsubsection{Environmental management}

Olowu et al. (2010) developed an electrochemical aptasensor for the detection of $17 \beta$ estradiol. 17 $\beta$-estradiol is an endocrine disrupting chemical (EDC), and thus interferes with the function of the endocrine system. EDCs are ubiquitous in the environment because of their widespread use in residential, industrial, and agricultural applications. Au electrodes were modified with poly(3,4-ethylenedioxythiopene) (PEDOT), onto which a layer of streptavidin was immobilized through $\mathrm{Au}$ nanoparticles and the linker 3,3'dithiodipropionic acid (DPA). The biotinylated $17 \beta$-estradiol aptamers were bound to this streptavidin layer. The electrochemical signal was a decrease in current between the redox mediator $\left[\mathrm{Fe}(\mathrm{CN})_{6}\right]^{-3 /-4}$ and the PEDOT due to the interference of the bound $17 \beta$-estradiol with the electron transfer. The aptasensor was found to be sensitive at concentrations as low as $0.02 \mathrm{nM}$ (Olowu et al., 2010).

\subsection{Whole-cell biosensor}

Whole-cell sensors provide some major advantages compared to other sensor types. Cells are able to detect effects of (complex) samples on living organisms. On the other hand, cells can also react to very low concentrations of certain molecules, making them more sensitive than other sensors using affinity molecules. The most popular format of whole-cell sensors involves the use of a reporter gene fused to a promoter that is influenced by the binding of a target analyte. Binding of the analyte to a cell receptor will set in motion a cascade of intracellular events, leading to the binding of a transcription factor to the promoter, which now controls the transcription of the reporter gene. This reporter gene usually codes for a fluorescent molecule or an enzyme generating a fluorescent molecule, which can be detected in response to the presence of the target analyte. However, some reports can be found using an electrochemical scheme.

\subsubsection{Clinical diagnostics}

Whole-cell sensors are not yet widespread in clinical diagnostics, although Akyilmaz et al. (2011) reported an electrochemical cell-based sensor for the detection of epinephrine. Epinephrine is one of the most important neurotransmitters in the mammalian central nervous system. It controls the nervous system in the execution of several biological reactions and chemical processes. Changes in its concentration may result in many diseases. Lyophilized White rot fungi cells in gelatine were immobilized onto a platinum $(\mathrm{Pt})$ electrode through glutaraldehyde as a cross-linker. Their enzyme laccase oxidizes epinephrine to epinephrine quinine, thereby reducing its cofactor $\mathrm{Cu}^{2+}$ to $\mathrm{Cu}^{+} . \mathrm{K}_{3}(\mathrm{CN})_{6}$ regenerates the cofactor and it is the increase in the reduction peak of $\mathrm{K}_{3}(\mathrm{CN})_{6}$ that was monitored after epinephrine exposure. The sensor showed a detection limit of $1.04 \mu \mathrm{M}$ (Akyilmaz et al., 2011). 


\subsubsection{Environmental management}

Whole-cell sensors are highly suitable for environmental monitoring as they can detect toxic effects of complex samples. These days, the pollution of groundwater due to rapid industrialization has prompted investigations of methods to detect water toxicity. Popovtzer et al. (2005) described the development of an electrochemical Si nano-biochip. Genetically engineered $E$. coli bacteria generated the signal. The promoter of their lacZ gene was deleted and replaced by the promoter of heat shock genes. In the presence of toxin, this promoter is activated and induces the production of $\beta$-galactosidase, the enzyme encoded by lac $Z$. The substrate of this enzyme, p-aminophenyl $\beta$-D-galactopyranoside (PAPG), was added and metabolized into p-aminophenol (PAP). PAP was subsequently oxidized at the Si electrode and the current was monitored. Concentrations as low as $0.5 \%$ of ethanol and $1.6 \mathrm{ppm}$ of phenol could be detected within 10 minutes after exposure to the toxic chemical (Popovtzer et al., 2005).

\section{Alternative transducer materials in biosensing}

The advances in biosensor development ultimately depend on the perpetual search for optimal transducer materials, allowing rapid, sensitive and selective biological signal detection and translation. Most of the sensor devices described made use of screen-printed carbon paste, $\mathrm{Au}$ or $\mathrm{Si}$ as a transducer. For materials to be considered as transducers, they must possess a number of important characteristics.

First of all, they need to be able to undergo biofunctionalization. Secondly, the sensor surfaces need to yield bio-interfaces that can be manufactured with a high reproducibility. Thirdly, the biofunctionalized sensor surfaces must be stable in liquid measurement conditions. Finally, the bio-interfaces will be integrated into micro-electronics, requiring the materials to be compatible with micro-electronic processes.

Unfortunately, Au and Si are not chemically stable and the bio-interfaces degrade upon contact with aqueous electrolytes (Nebel et al., 2007), which limits their use for continuous monitoring and endows them with a disposable character, leading to environmental issues. The biggest disadvantage of carbon paste electrodes is the production reproducibility. Each carbon paste unit is an individual, and the physical, chemical and electrochemical properties may differ from one preparation to another.

Diamond has become an attractive alternative candidate for its use as a transducer material in bio-electronics. It is the only material that is compatible with processes applied in microelectronics that does not show any degradation in electrolytes, even at fairly high potentials. Moreover, the naturally insulating diamond can be made into a semiconductor by a process called doping. Doping involves the introduction of impurity atoms into the carbon lattice. Two types of diamond doping exist: p-type doping and n-type doping (Nebel et al., 2007). The difference between a p-type and an n-type semiconductor is graphically presented in figure 2 .

Introduction of impurity atoms of group III, for instance boron (B) atoms, into diamond results in p-type doping. In the diamond lattice structure, each $C$ atom has 4 electrons in its outer, valence shell, that are shared with 4 other $C$ atoms. The valence band, now containing 8 electrons per $\mathrm{C}$ atom, is completely filled, forming a very stable crystal. B has only 3 electrons in its valence shell. When B is introduced into the lattice, an electron deficiency, or a positively charged hole, is created in the energy level directly above the valence band of diamond, called the acceptor level. This hole can be filled by the movement of an electron 
from the valence shell of a neighbouring $C$ atom into the hole of the B atom. B is thus called an acceptor atom. By filling the electron vacancy, a new hole is now created in the valence shell of the $\mathrm{C}$ atom that donated the electron, which itself can be filled by another neighbouring electron. The result is a movement of positively charged holes in the valence band of diamond. These holes are thus called the majority charge carriers.

Introduction of impurity atoms of group IV, such as phosphorous $(\mathrm{P})$ atoms, into diamond results in n-type doping. $\mathrm{P}$ has 5 electrons in its valence shell. When $\mathrm{P}$ is incorporated into the diamond lattice, a situation is created where additional free electrons are supplied to the diamond lattice. Hence, $\mathrm{P}$ is called a donor atom. These electrons are very loosely bound in the diamond crystal, and occupy an energy level directly below the conduction band, termed the donor level. The result is a movement of negatively charged electrons in the conduction band of diamond. These electrons are the majority charge carriers. In 1997, Koizumi et al. (1997) were the first to succeed in producing n-type doped SCD using phosphine (Koizumi et al., 1997).

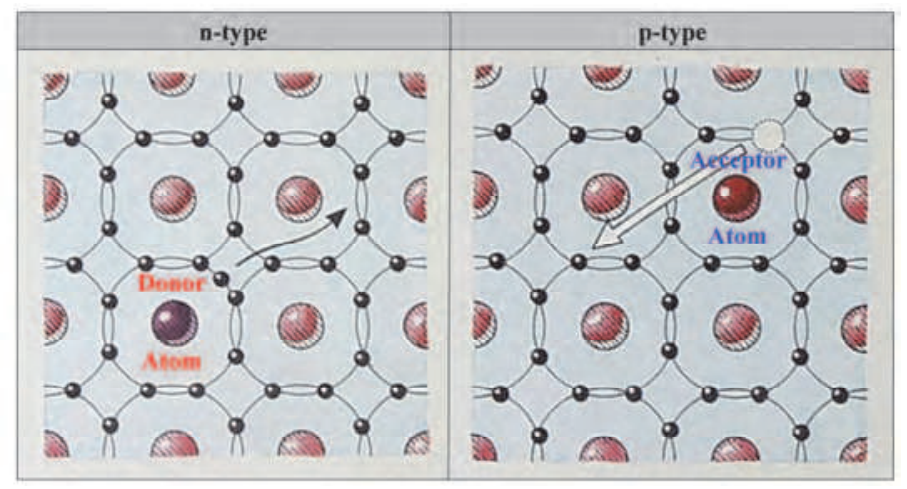

Fig. 2. Schematic diagram of an n-type and p-type semiconductor material at the atomic level.

\subsection{Functionalization}

\subsubsection{Adsorption}

Generally, physical adsorption results in significant losses of biomolecules from the surface because of the rather weak bonds involved to immobilize them. Moreover, physical adsorption leads to random orientations of the molecules, more often than not rendering the part that engages in target recognition inaccessible, thereby lowering device sensitivity. However, in some cases, adsorption is the preferred method of attachment. Some noncovalent binding approaches even yield a firmly immobilized and well-oriented biomolecule layer. Streptavidin-modified surfaces bound with biotinylated biomolecules result in the strongest non-covalent bond known. The streptavidin-biotin complexes are also extremely stable over a wide range of temperatures and $\mathrm{pH}$ (Gorton, 2005). On the other hand, strong hydrophobic interactions between hydrogen $(\mathrm{H})$-terminated surfaces and biomolecules are also found to be sufficient for reliable biorecognition and detection. Furthermore, when an attachment needs to be obtained between a surface and macroscopic entities, such as cells or tissues, joint forces of membrane protein interactions with each other and the surface contribute to a very stable biological meshwork. 


\section{Antibodies}

Our group constructed an impedimetric immunosensor directed against C-Reactive Protein (CRP), an acute phase protein serving as a marker for cardiovascular disease, based on the physical adsorption of anti-CRP to H-terminated nanocrystalline diamond (NCD), since Silin et al. (1997) demonstrated the suitability of hydrophobic surfaces for antibody adsorption. They postulated that the protein adsorption to this type of surface was a multistep process, probably initiated by interaction of hydrophobic residues, that have temporarily become exposed at the surface of the protein, with the hydrophobic surface. This initial interaction is then followed by multipoint interactions due to various degrees of protein denaturation, making desorption from the surface extremely difficult (Silin, V et al., 1997). The experiments of our group indicated that the biological activity of the antibodies was not hampered (Bijnens et al., 2009).

\section{Cells}

Chen et al. (2009) studied the suitability of ultra-nanocrystalline diamond (UNCD) to be used as a biomaterial for the growth and differentiation of neural stem cells (NSCs). H- and oxygen (O)-terminated UNCD films were compared with for their influence on the growth, expansion and differentiation of NSCs. H-terminated UNCD films spontaneously induced cell proliferation and neuronal differentiation. O-terminated UNCD films were also shown to further improve neural differentiation, with a preference to differentiate into oligodendrocytes. Hence, controlling the surface properties of UNCD could manipulate the differentiation of NSCs for different biomedical applications (Chen et al., 2009).

Also, Smisdom et al. (2009) cultured transfected Chinese Hamster Ovary (CHO) cells on bare, H-terminated, and O-terminated NCD and microcrystalline diamond (MCD) surfaces. Optical and biochemical analyses show that compared to glass controls, growth and viability of the $\mathrm{CHO}$ cells were not significantly affected (Smisdom et al., 2009).

\subsubsection{Covalent attachment}

Covalent attachment of biomolecules to diamond is the immobilization technique of choice for biosensor fabrication. It results in a stable and long-term modification of the substrate with oriented biomolecules. The surface of the diamond can be modified to present desired functionalities. The bioreceptor molecules can subsequently be coupled to these functional groups through their own range of intrinsic or custom functionalities.

\section{DNA and aptamers}

chemical functionalization

Ushizawa et al. (2002) reported the wet-chemical modification of diamond powder (1 - 2 $\mu \mathrm{m})$ with thymidines (T). First, the surface of the diamond powder was oxidized to its surface oxides (carboxylic acid [COOH], hydroxyl $[\mathrm{OH}]$, acid anhydride) by immersion into a heated mixture of sulphuric acid $\left(\mathrm{H}_{2} \mathrm{SO}_{4}\right)$ and nitric acid $\left(\mathrm{HNO}_{3}\right)$. Next, the $\mathrm{COOH}$ modified diamond was treated with thionyl chloride $\left(\mathrm{SOCl}_{2}\right)$ and $\mathrm{T}$, resulting in a $\mathrm{T}$ modified diamond surface. DNA molecules generated through PCR amplification could be covalently attached to the T-modified surface via a simple ligation reaction. PCR has the interesting characteristic of adding an adenine (A) base to the $3^{\prime}$ end of each amplified DNA molecule. These $3^{\prime}$ A-overhangs were exploited in the ligation to the T-modified surface. Diffuse Reflectance Infrared Fourier-Transform spectroscopy (DRIFT) was used to verify the presence of DNA on the surface (Ushizawa et al., 2002). A summary of their reaction process is given in figure 3 . 


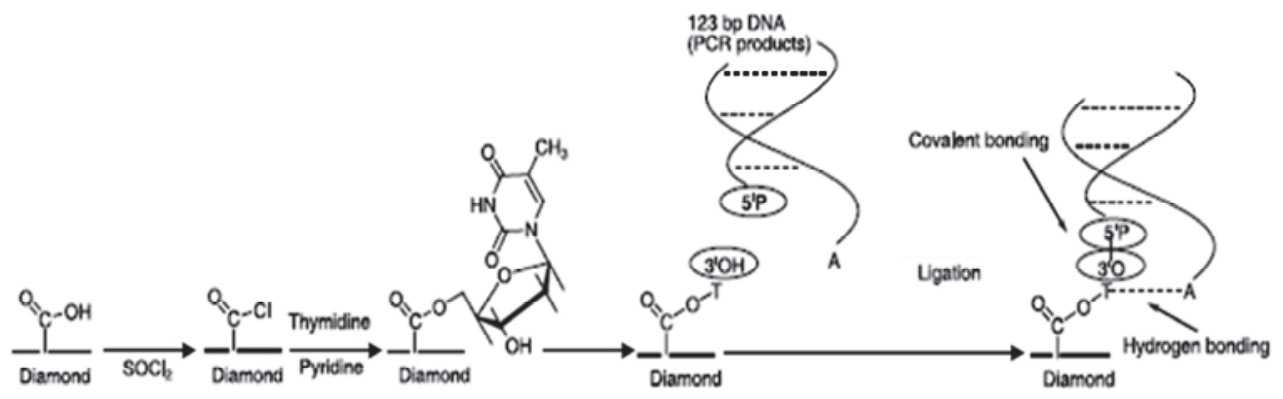

Fig. 3. Reaction process used by Ushizawa et al. (2002) for the covalent attachment of PCRamplified dsDNA to T-modified diamond powder. Adapted from (Ushizawa et al., 2002).

electrochemical functionalization

Single-crystalline diamond (SCD) of p-type nature has been covalently modified with DNA molecules through an electrochemical procedure by Wang et al. (2004). They used a threeelectrode configuration with a SCD working electrode, a $\mathrm{Pt}$ counter electrode and a silver/silver chloride $(\mathrm{Ag} / \mathrm{AgCl})$ reference electrode. The p-type SCD working electrode was treated with the diazonium salt 4-nitrobenzene-diazonium tetrafluoroborate. This salt was reduced in acetonitrile to nitrophenyl using Cyclic Voltammetry (CV) and attached to the SCD surface in a nitrogen gas $\left(\mathrm{N}_{2}\right)$-purged glove-box. The nitrophenyl groups were subsequently reduced to aminophenyl groups, resulting in a $\mathrm{NH}_{2}$-modified SCD surface. This $\mathrm{NH}_{2}$-modified SCD could then be modified downstream with the heterobifunctional cross-linker molecule sulphosuccinimidyl-4-(N-maleimido-mehyl)cyclohexane-1carboxylate (SSMCC). The N-hydroxy-succinimide (NHS)-ester group of SSMCC reacts with the $\mathrm{NH}_{2}$-groups on the NCD to form amide $(\mathrm{NH})$ bonds. $\mathrm{SH}$-modified ssDNA could then be linked to the $\mathrm{COOH}-$ moiety of SSMCC at room temperature, resulting in a covalent bond (Wang et al., 2004). This procedure is outlined in figure 4.

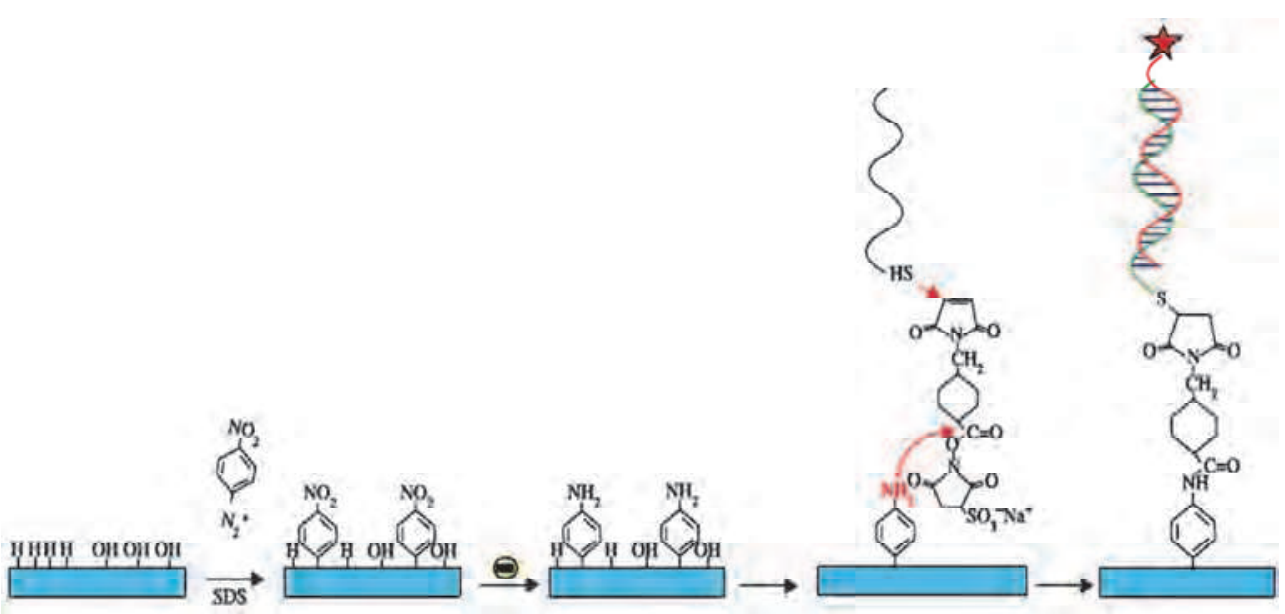

Fig. 4. Reaction process used by Wang et al. (2004) for the covalent attachment of SH-ssDNA to aminophenyl-modified p-type SCD. Adapted from (Nebel et al., 2007). 
$\mathrm{Gu}$ et al. (2005) functionalized p-type diamond with a PANI/polyacrylic acid (PAA) composite polymer films using $\mathrm{CV}$. The p-type diamond working electrode was treated with the aniline and PAA monomeric solution, and by potential cycling the monomers were polymerized onto the electrode. In a final step, $\mathrm{NH}_{2}$-modified ssDNA was covalently attached to the exposed $\mathrm{COOH}$-groups of the PANI/PAA polymeric film by 1-ethyl-3-(3dimethylaminopropyl)-carbodiimide (EDC) (Gu et al., 2005).

photochemical functionalization

Undoped, H-terminated NCD surfaces were covered with trifluoro-acetamide acid (TFAAD) inside a $\mathrm{N}_{2}$-purged Teflon reaction chamber by Yang et al. (2004). This is a 10amino-dec-1-ene molecule, protected with a trifluoro-acetic acid group at one end. The other end is terminated by a $\mathrm{C}=\mathrm{C}$ double bond. The chamber was sealed with a quartz window, allowing the passage of UV-light from a low-pressure mercury lamp $\left(0.35 \mathrm{~mW} . \mathrm{cm}^{-2}\right.$ measured at the sample surface) for $12 \mathrm{~h}$. This illumination process caused a covalent bond to be formed between the TFAAD and the H-terminated NCD, exposing the trifluoro-acetic acid groups at the NCD surface (Yang et al., 2002). After TFAAD attachment, the trifluoroacetic acid groups were removed by immersion into a hydrochloric acid $(\mathrm{HCl}) /$ methanol solution, forming $\mathrm{NH}_{2}$-modified NCD surfaces. These were subsequently exposed to the heterobifunctional cross-linker molecule SSMCC. SH-modified ssDNA molecules could then be linked to the SSMCC in the same way as described above. Figure 5 represents the reaction steps that were employed (Yang et al., 2004).

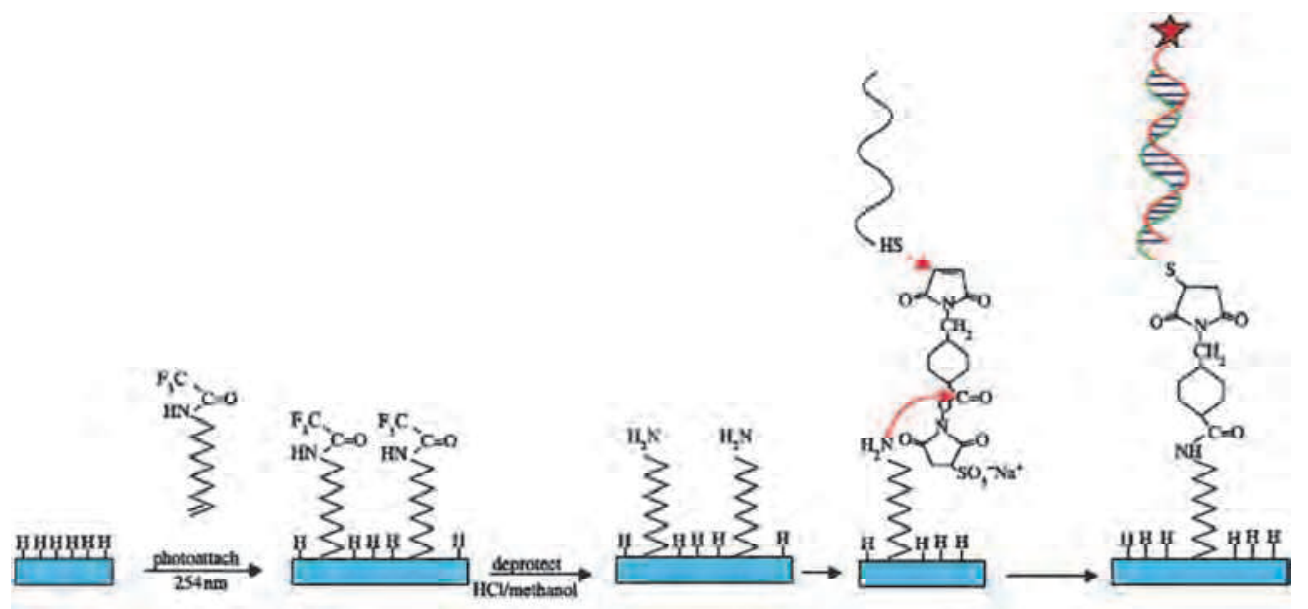

Fig. 5. Reaction process used by Yang et al. (2004) for the covalent attachment of thiolated ssDNA to photochemically activated NCD. Adapted from (Nebel et al., 2007).

Our group devized a procedure for the covalent attachment of DNA, which was a simple, two-step photochemical method using a flexible linker and a zero-length cross-linker, displayed in figure 6. Undoped, H-terminated NCD was immersed in a fatty acid molecule, 10-unedecenoic acid (10-UDA), consisting of a reactive $C=C$ double bond on one end, and a $\mathrm{COOH}$-group on the other end. A $20 \mathrm{~h}$ illumination with UV-light $\left(2.5 \mathrm{~mW} . \mathrm{cm}^{-2}\right)$ also caused a covalent bond to be formed between the 10-UDA and the H-terminated NCD, yielding a $\mathrm{COOH}$-modified $\mathrm{NCD}$ surface. $\mathrm{NH}_{2}$-modified ssDNA could then be reacted with these 
COOH-groups via EDC, resulting in covalently bound ssDNA molecules to NCD through a $\mathrm{NH}$ bond. The presence of the 10-UDA linker molecule offers mobility to the attached DNA, increasing their availability for hybridization reactions. Moreover the EDC cross-linker did not remain present in the eventual $\mathrm{NH}$ bond, resulting in a smaller distance between NCD and DNA (Christiaens et al., 2006), (Vermeeren et al., 2008).

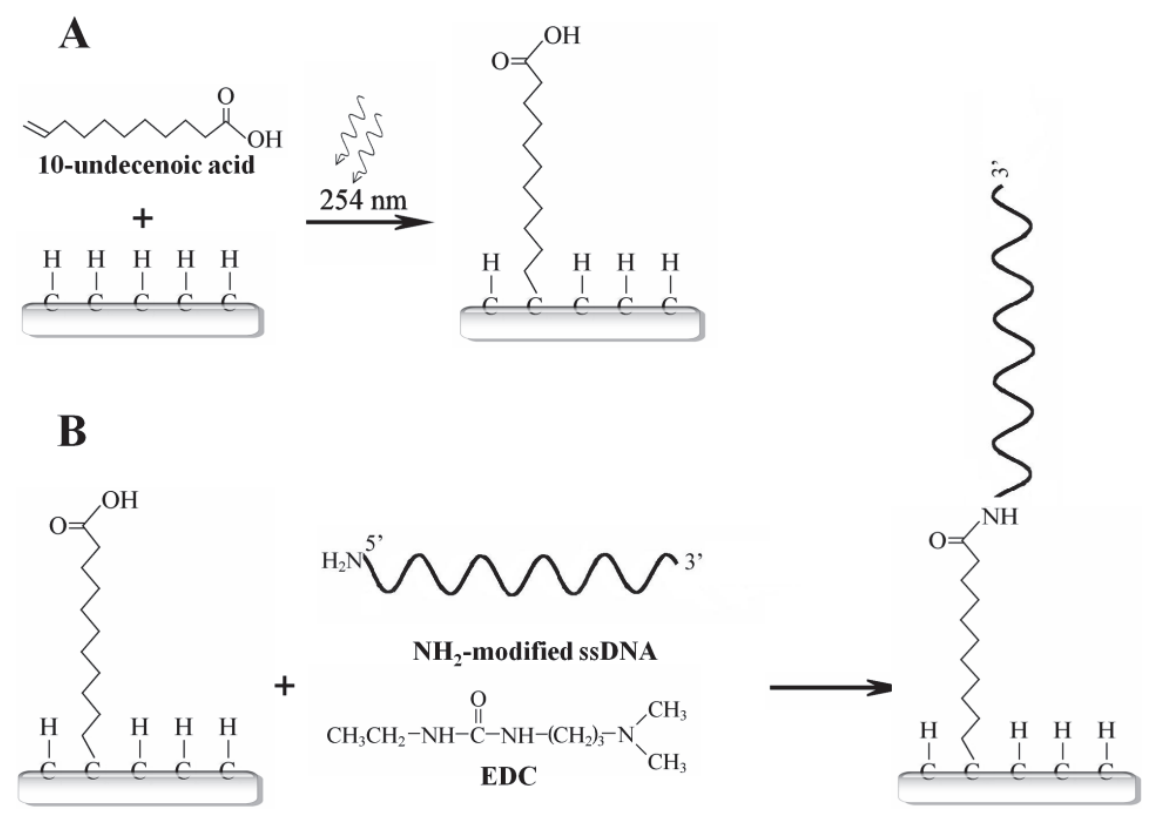

Fig. 6. Photoattachment of 10-UDA acid to the NCD surface through irradiation with $254 \mathrm{~nm}$ UV-light (A). Covalent attachment of $\mathrm{NH}_{2}$-modified ssDNA to 10-UDA on an NCD suface using an EDC-mediated reaction (B).

\section{Antibodies}

Although immunosensors are often based on physical adsorption of the antibodies to the transducer, as described above, signal drift is a very common side effect associated with this manner of attachment (Carrara et al., 2008). This is the reason that a covalent attachment method is preferred in the more recent publications. Since antibodies, being proteins, possess $\mathrm{NH}_{2}$-groups, the EDC-route described previously for the covalent attachment of $\mathrm{NH}_{2}$-modified DNA is a very popular method. However, the procedure needs to be adjusted into a two-step process because antibodies also possess $\mathrm{COOH}$-groups. The onestep procedure as described for DNA would lead to a chain formation of end-to-end attached antibodies instead of antibodies attached to the COOH-modified surface. This is the reason that, in a first step, NHS is attached to the COOH-terminated surface using EDC. In a second step, the antibodies are added, that switch places with the NHS, the latter functioning as leaving group. This way, EDC never comes into contact with the antibodies, and chain formation is avoided (Quershi et al., 2009). However, it is documented that the $\mathrm{NH}_{2}$-terminus of antibodies are located at the antigen-binding variable regions, and not many aminoacids with $\mathrm{NH}_{2}$-containing side groups, like lysine, are present in the constant 
Fc region of the antibodies. Although a more stable molecular layer is obtained with this procedure, possibly decreasing signal drift, it is doubtful that the orientation of the attached antibodies will be optimal (Harlow et al., 1999).

For this reason, Jung et al. developed an alternative attachment procedure for antibodies. In a first step, they covalently attached a 13 aminoacid cyclic $\mathrm{FC}_{\mathrm{C}}$ binding peptide to a $\mathrm{COOH}-$ modified surface using the two-step EDC-NHS route. In a second step, they added the antibodies, that will be captured by their Fc regions, resolving the orientation issue (Jung et al., 2008). There is no covalent bond between the antibodies and the Fc binding proteins, but the well-organized monolayer of molecules will possibly suffice to stabilize the electronic signal.

\subsection{Electrochemical characterization}

Because of the increasing focus on point-of-care analyte detection, electrochemical biosensors are most popular. Considering the five requirements, electrochemical biosensors are sensitive, specific, cheap, easy to miniaturize, and can detect the analyte recognition in real-time, making them fast. Moreover, the continuous response of the electrochemical sensor allows computerized control, simplifying the electrochemical detection, and lowering the cost even more.

Electrochemical biosensors can be subdivided into amperometric, potentiometric, impedimetric, and field effect transistor (FET)-based biosensors. However, only impedimetric, and field effect transistor (FET)-based biosensors have the potential to allow for real-time and label-free target detection, which are key requirements for point-of-care application. Unfortunately, it has generally been accepted that FET-based biosensing is problematic, to say the least. The counter-ion screening effect is the main reason for this fact. Charged groups in the molecular layer on top of the electrode will be neutralized by the surrounding counter-ions that are present in the buffer solution during measurement. This will result in net uncharged molecular layers, causing the biological recognition event to go undetected with FET-based devices. Hence, only Electrochemical Impedance Spectroscopy (EIS)-based biosensing will be discussed.

\subsubsection{Theory of Electrochemical Impedance Spectroscopy (EIS)}

In an ideally resistive electrical circuit, the elements such as the voltage $(V)$, current $(I)$, and resistance $(R)$, behave independent of the voltage frequency, and are governed by Ohm's law:

$$
R=\frac{V}{I}
$$

Often, however, the electrical circuit is not purely resistive, but also contains inductive $(L)$ and capacitive $(C)$ components. If in this case an alternating $(A C)$ voltage is applied, $I$ and $V$ become out of phase, and are frequency-dependent. For this reason, the oscillating $V$ and $I$ will be written as complex entities, as a function of their magnitudes $V_{0}$ and $I_{0}$, respectively, the phase shift $\varphi$ of $I$ with respect to $V$, and the frequency $\omega$ :

$$
V(t)=V_{0} \exp (j \omega t)
$$




$$
I(t)=I_{0} \exp [j(\omega t-\varphi)]
$$

Consequently, the simple $R$ is replaced by the complex impedance, $Z$. Being a complex entity, $Z$ is also defined by its magnitude, $Z_{0}$, and its phase shift, $\varphi$ :

$$
Z=\frac{V(t)}{I(t)}=Z_{0} e^{j \varphi}=Z_{0}(\cos \varphi+j \sin \varphi)
$$

where $Z_{0}(\cos \varphi)$ and $Z_{0}(\sin \varphi)$ are the real part, $\operatorname{Re}(Z)$, and the imaginary part, $\operatorname{Im}(Z)$, of the complex impedance, $Z$, respectively. In other words, impedance signifies opposition to current flow in an alternating current (AC) electrical circuit.

Two popular ways exist to graphically represent the impedance data: a Bode plot and a Nyquist plot. A Bode plot depicts the magnitude of the complex impedance, $Z$, or the phase shift, $\varphi$, as a function of frequency, $\omega$. Usually, a logarithmic scale is used for the magnitude and the frequency. Figure 7 shows an example of a Bode plot of the complex impedance, $Z$, and of the phase shift, $\varphi$, for a parallel $R C$ circuit.

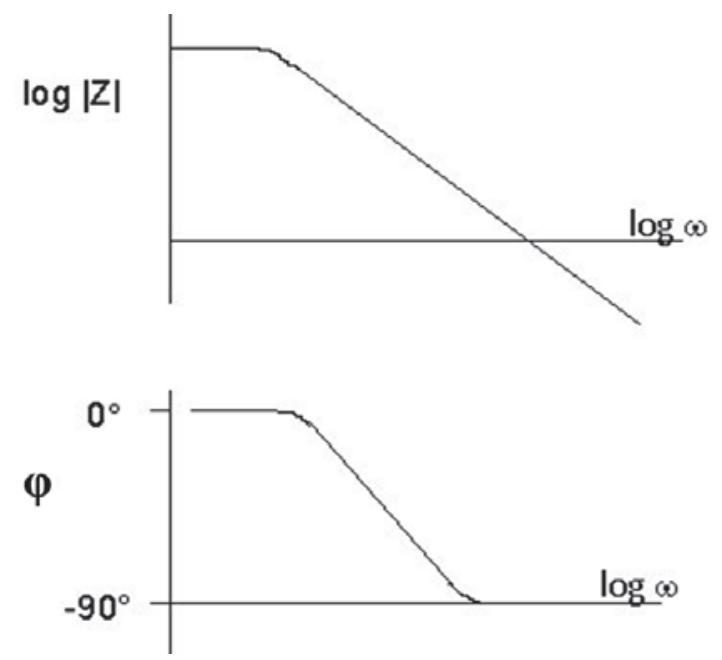

Fig. 7. Bode plot of the complex impedance, $Z$ (upper panel), and of the phase shift, $\varphi$ (lower panel), versus frequency, $\omega$, for a parallel $R C$ circuit. Both the $\mathrm{X}$-axis and the $\mathrm{Y}$-axis are represented by a logarithmic scale.

A Nyquist plot displays the imaginary part and the real part which make up the complex impedance, $Z$. The negative form of $\operatorname{Im}(Z)$ is plotted on the $Y$-axis, while $\operatorname{Re}(Z)$ is presented on the $\mathrm{X}$-axis. Figure 8 shows a Nyquist plot of the same parallel $R C$ circuit as in figure 7.

Each point in this Nyquist plot represents the complex impedance, $Z$, at one frequency, $\omega$. When drawing a vector through the zero-point to this point, the magnitude, $|Z|$, and the phase shift, $\varphi$, can be deduced. The frequency, $\omega$, decreases from right to left in the plot (Young et al., 1999). 


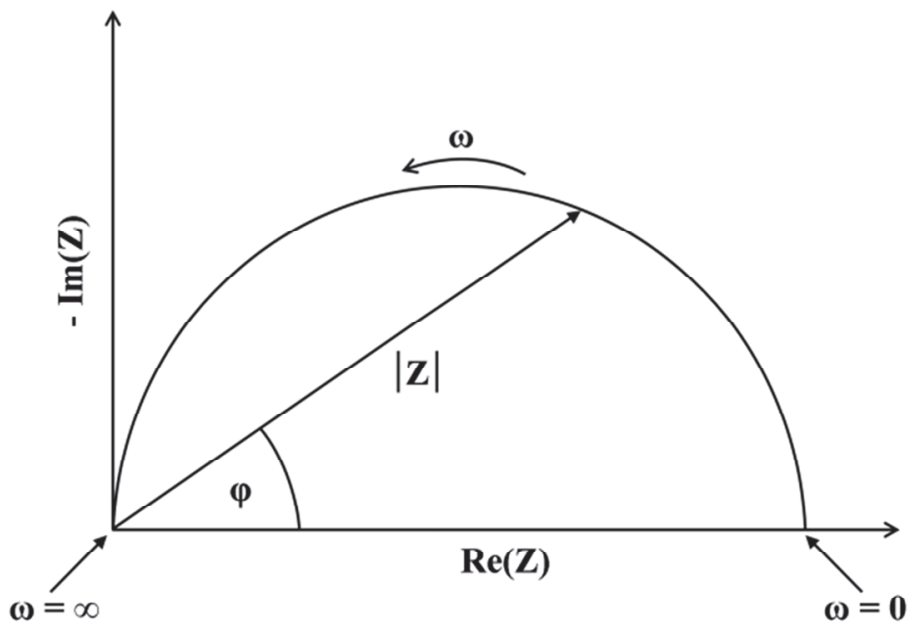

Fig. 8. Nyquist plot, displaying $-\operatorname{Im}(Z)$ versus $\operatorname{Re}(Z)$, for a parallel $R C$ circuit.

When a semiconductor electrode is placed into contact with an electrolyte, the Fermi level, $\mathrm{E}_{\mathrm{F}}$, of the semiconductor and the chemical potential of the electrolyte, $\mu$, are initially not in equilibrium. Two alternative events can occur to obtain the necessary thermodynamic equilibrium, depending on the type of semiconductor. These are shown in figure 9.

When a p-type semiconductor is placed in contact with a liquid, electrons move from the electrolyte into the semiconductor, thereby depleting the positively charged holes in the material and creating a region just below the semiconductor surface where no majority charge carriers exist. This region is called the depletion zone or the space-charge region. When no more electrons move into the semiconductor, thermodynamic equilibrium is reached between $\mathrm{E}_{\mathrm{F}}$ and $\mu$, resulting in a downward bending of the valence and conduction bands in the p-type semiconductor.

When an n-type semiconductor is placed in contact with a liquid, electrons move from the semiconductor into the electrolyte, also decreasing the amount of majority charge carriers in the material and creating a depletion zone or space-charge region just below the semiconductor surface. At thermodynamic equilibrium, the result is an upward band bending. These phenomena occurring in the semiconductor are called field-effects.

Any chemical modification in the electrode-electrolyte interface, for instance the binding of an antigen to an antibody-modified electrode, or the hybridization of target ssDNA to a ssDNA-modified electrode, will alter this equilibrium, and hence the degree of band bending. In other words, the depletion zone in the semiconductor can be made wider or narrower by external events. A narrowing of the depletion zone corresponds to a decrease in impedance, since the obstacle for charge carriers that want to cross this space-charge region decreases. A widening of the depletion zone corresponds to an increase in impedance, since the obstacle for charge carriers that want to cross this space-charge region increases. Since DNA is negatively charged, it will likely exert a field-effect in a semiconductor when bound to its surface. EIS is therefore often used as a mechanism to detect hybridization events.

When ssDNA is attached to the surface of a p-type semiconductor, their negative charges attract the holes in the semiconductor to the surface-DNA interface. The space-charge region 
becomes narrower, and the downward band bending becomes less steep. Moreover, additional negative charges brought about by hybridization will increase this effect even more. The result is a decrease in impedance.

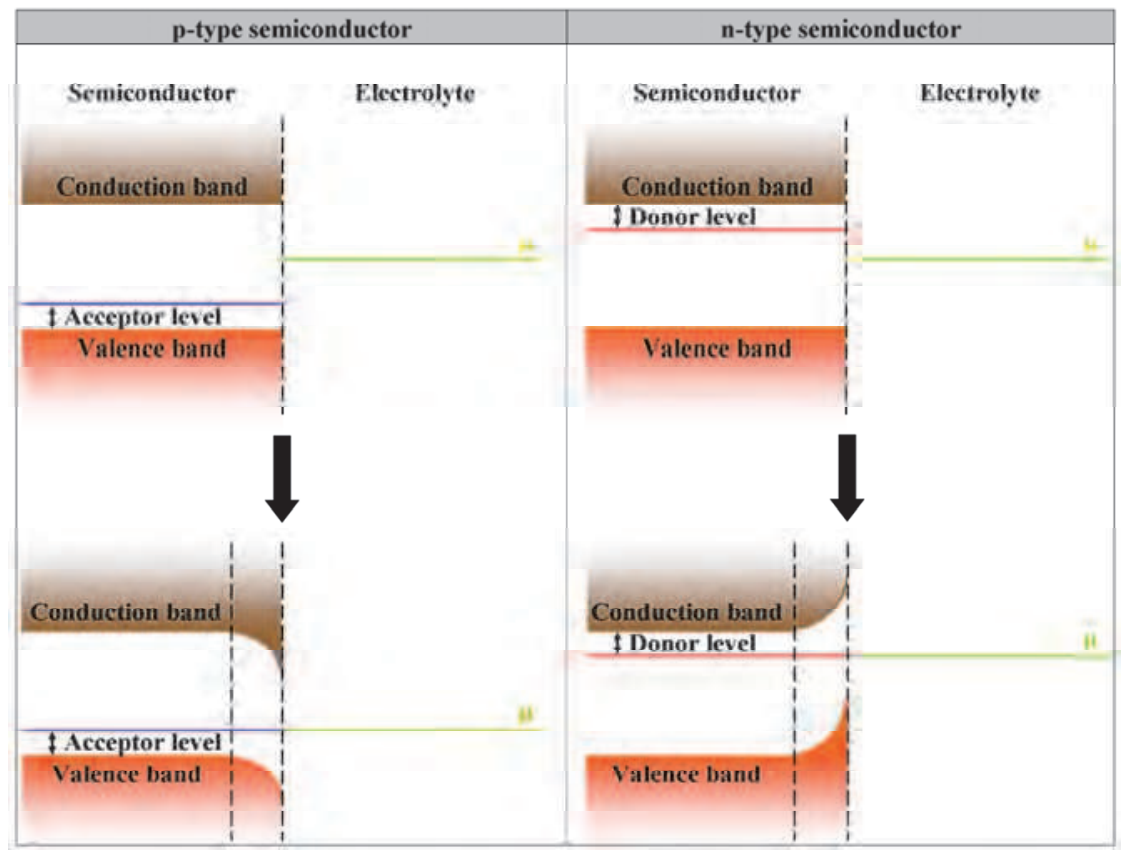

Fig. 9. Generation of thermodynamic equilibrium in p-type (left panel) and n-type (right panel) semiconductors through downward and upward band bending, respectively.

When ssDNA is attached to the surface of a n-type semiconductor, their negative charges repel the electrons in the semiconductor. The space-charge region becomes wider, and the upward band bending becomes more pronounced. This effect is again amplified by hybridization.

In EIS, an AC potential is generated over a range of frequencies between the biologically modified semiconductor working electrode and a counter electrode. The impedance is subsequently measured between these two electrodes, through the electrolyte, for each frequency in the analyzed frequency range. By modelling the observed impedance effects with an electrical circuit, one can associate certain effects with changes in electrical elements, further elucidating the events at the molecular level. It is a useful tool for label-free and realtime target detection. This decreases cost and analysis time (Nebel et al., 2006), (Young et al., 1999), (Memming, 2000), (Chakrapani et al., 2007).

\subsubsection{Impedimetric DNA-sensors}

Impedimetric diamond-based DNA-sensors are very popular in the literature. Yang et al. (2004) monitored selective DNA hybridization using EIS. H-terminated NCD working electrodes of p-type nature were covalently modified with SH-ssDNA molecules. A Pt foil and $\mathrm{a} \mathrm{Ag} / \mathrm{AgCl}$ wire were used as counter and reference electrode, respectively. They 
showed that measurements at open-circuit potential displayed a significant decrease in impedance at frequencies of $>10^{4} \mathrm{~Hz}$, even in real-time, when the NCD electrode was exposed to complementary target ssDNA, while 4-base mismatch sequences were easily discriminated. By electrical circuit modelling, they attributed this effect to a hybridizationinduced field-effect in the NCD film (Yang et al., 2004). Gu et al. (2005) covalently immobilized $\mathrm{NH}_{2}$-modified ssDNA onto p-type diamond with a PANI/PAA composite polymer. A three-electrode system was used for EIS. The p-type diamond served as a working electrode, the counter electrode was a Pt wire and the reference electrode was $\mathrm{Ag} / \mathrm{AgCl}$. They observed an impedance decrease, this time in the lower frequency regions $(10-100 \mathrm{~Hz})$ upon complementary hybridization, and a decrease in electron-transfer resistance to the electrode. Electric circuit modelling, using the same circuit model as Yang, attributed this lower frequency region to reflect the polymer/molecular double-layer. They suggest that hybridization with complementary DNA decreases the resistance and increases the capacity of the polymer, both due to an increase in ionic density at the interface. The space-charge region of the p-type diamond electrode was reflected at frequencies of $\sim 1000$ $\mathrm{Hz}$. They found that DNA hybridization also altered the electrical response of the electrode through a field-effect, resulting in a decreased impedance in this space-charge region. The linear range of target ssDNA detection was 50 to $200 \mathrm{nM}$, with a detection limit of $20 \mathrm{nM}$. They obtained SNP sensitivity (Gu et al., 2005). In our group, we investigated the possibility of SNP detection on NCD using EIS. Probe ssDNA molecules were covalently attached to $\mathrm{COOH}$-modified NCD working electrodes. The frequency-dependent change in impedance was analyzed in real-time with complementary ssDNA and ssDNA containing a SNP. SNP discrimination was possible in real-time during denaturation at the highest frequency of 1 $\mathrm{MHz}$ within 5 minutes. This SNP sensitivity is clinically relevant since numerous genetic illnesses are caused by point mutations. It is reflected in a fast impedance decrease for the SNP-duplexes and a slower impedance decrease for the complementary duplexes. Since complementary duplexes are stable molecules, they have a rather high melting temperature, reflected in a slow impedance decrease rate. SNP-duplexes are much less stable than complementary duplexes, and hence they have a lower melting temperature. This is reflected in a faster impedance decrease rate. This exact principle of SNP differentiation based on different melting temperatures is also the basis of Denaturing Gradient Gel Electrophoresis (DGGE) used for SNP identification, but it is the first time that this is reported with an electronic technique. Like is possible with DGGE, EIS could also enable mutation identification, since different types of mutations will also yield duplexes with different melting temperatures (Vermeeren et al., 2007).

\subsubsection{Impedimetric immunosensors}

Impedimetric diamond-based immunosensors are also widespread, and it has been established that antigen recognition causes an increased thickness in the molecular layer, leading to a clear capacitive effect in the impedance spectrum. Yang et al. (2007) used EIS to directly detect antigen-antibody binding on diamond and $\mathrm{Si}$. A Pt foil and $\mathrm{Ag} / \mathrm{AgCl}$ served as a counter and a reference electrode, respectively. They covalently modified n-type and ptype Si and p-type NCD with human IgG and IgM. The Fc regions of these covalently attached IgG and IgM antibodies served as antigens for anti-human IgG and anti-human IgM. They succeeded in real-time and label-free detection of selective antigen recognition, and observed an increase in impedance at frequencies $>10^{4} \mathrm{~Hz}$ for the p-type substrates, and a decrease in impedance in the same frequency region for n-type Si. Circuit modelling 
showed that the frequency region sensitive for antigen recognition is dominated by the space-charge region of the electrode. When positively charged anti-IgG and anti-IgM approach a p-type surface, the holes are repelled and widen the depletion zone, increasing the impedance in the space-charge region. When positively charged anti-IgG and anti-IgM approach a n-type surface, the electrons are attracted, which narrows the depletion zone, decreasing the impedance in the space-charge region. The detection limit for real-time selective IgG detection was $42 \mathrm{nM}$ in 12 minutes (Yang et al., 2007). In our group, as already mentioned, H-terminated NCD working electrodes were modified with anti-CRP by simple physical adsorption. A Au wire in contact with the reaction fluid served as a counter electrode. The selective antigen recognition was analyzed in real-time, and the detection limit was found to be $10 \mathrm{nM}$, which was in the physiologically relevant range, and could be discriminated within 10 minutes (Bijnens et al., 2009).

\subsubsection{Impedimetric aptasensors}

Tran et al. (2011) described an impedimetric aptasensor for the detection of human IgE. Human IgE has been demonstrated to be a mediator in allergic reactions. Allergenicity is a major health concern in both children and adults. Approximately $2 \%$ of adults and $8 \%$ of children suffer from allergenicity. Allergic reactions are caused by exposure of the skin to chemicals, or of the respiratory system to pollen or dust, and consumption of certain food products. The total IgE level in serum is therefore widely considered as a marker for atopic diseases. IgE aptamers were covalently attached to NCD electrodes, and the impedimetric response was monitored continuously during $\operatorname{IgE}$ incubation. They obtained a detection limit of $0.03 \mu \mathrm{g} / \mathrm{ml}$ in serum (Tran et al., 2011).

\section{Future research}

Science is focusing more and more on the development of point-of-care biosensors to diagnose diseases, assess food quality, and monitor the environment. The five requirements that need to be met are high sensitivity, high specificity, high analysis speed, low cost, and portability. Speed and low cost are obtained by analyzing in real-time and working in a label-free setting, respectively. Biosensors based on an impedimetric read-out offer the most potential to combine all of these factors.

However, an electrochemical read-out has implications on the choice of transducer material. EIS implies a semiconducting material to transducer the biological event into a readable signal, but most semiconductors are sensitive to hydrolysis when in contact with an electrolyte. This causes an unstable molecular layer, leading to signal drift. This issue becomes of less importance when a disposable, single-use application of the sensor is envisaged. However, in some circumstances, such as continuous measurements of cardiovascular markers or environmental toxins, signal stability is paramount. Semiconducting diamond could be a promising alternative, because extremely stable C-C bonds can be formed between the material and all kinds of bioreceptor molecules.

Another aspect that needs attention is the fact that no conclusion, be it in the medical, environmental, or food industry, is reached by the monitoring of one single analyte. Multiplexing is necessary to reach a reliable and well-founded diagnosis. Only few reports have mentioned the simultaneous detection of multiple markers, but rarely more than two. To extend the concept of a point-of-care sensor, that is functional under controlled conditions, into a device that is able to be used in a real application field, the transducer will need to be arrayed, and each spot will have to be read out separately, and reach the same 
sensitivity and specificity as the monofunctionalized version. A firm collaboration between bioelectronics and bioengineering is necessary to succeed in this task.

In order to reach higher sensitivities and lower detection limits, the use of cells as actual biosensors also merits further exploration. Because of the cell's membrane receptors, it is it's job to respond to very low concentrations of analytes. Recombinant DNA technology could allow the construction of a custom-made receptor, leading to a reporter cell with tailored specificity.

For all of the further refinements of biosensor development, it is clear that a strong interdisciplinary relationship and collaboration is necessary between bioelectronics, bioengineering, molecular biology, physics, and chemistry. Only then will we evolve towards the actual implementation of point-of-care biosensors.

\section{References}

Akyilmaz, E., Turemis, M., \& Yasa, I. (2011). Voltammetric determination of epinephrine by White rot fungi (Phanerochaete chrysosporium ME446) cells based microbial biosensor. Biosens.Bioelectron., Vol. 26, No. 5, pp. (2590-2594)

Bijnens, N., Vermeeren, V., Daenen, M., Grieten, L., Haenen, K., Wenmackers, S., Williams, O. A., Ameloot, M., VandeVen M., Michiels, L., \& Wagner, P. (2009). Synthetic diamond films as a platform material for label-free protein sensors. Phys.Stat.Sol.(a), Vol. 206, No. 3, pp. (520-526)

Bonel, L., Vidal, J. C., Duato, P., \& Castillo, J. R. (2010). An electrochemical competitive biosensor for ochratoxin A based on a DNA biotinylated aptamer. Biosens.Bioelectron., in press

Cai, W., Peck, J. R., van der Weide, D. W., \& Hamers, R. J. (2004). Direct electrical detection of hybridization at DNA-modified silicon surfaces. Biosens.Bioelectron., Vol. 19, No. 9, pp. (1013-1019)

Carrara, S., Bhalla, V. K., Stagni, C., Benini, L., Riccò, B., \& Samorì, B. (2008). Improving probe immobilization for label-free capacitive detection of DNA hybridization on microfabricated gold electrodes. Sensors and Transducers, Vol. 88, pp. (31-39)

Chakrapani, V., Angus, J. C., Anderson, A. B., Wolter, S. D., Stoner, B. R., \& Sumanasekera, G. U. (2007). Charge transfer equilibria between diamond and an aqueous oxygen electrochemical redox couple. Science, Vol. 318, No. 5855, pp. (1424-1430)

Chemburu, S., Wilkins, E., \& Abdel-Hamid, I. (2005). Detection of pathogenic bacteria in food samples using highly-dispersed carbon particles. Biosens.Bioelectron., Vol. 21, No. 3, pp. (491-499)

Chen, Y. C., Lee, D. C., Hsiao, C. Y., Chung, Y. F., Chen, H. C., Thomas, J. P., Pong, W. F., Tai, N. H., Lin, I. N., \& Chiu, I. M. (2009). The effect of ultra-nanocrystalline diamond films on the proliferation and differentiation of neural stem cells. Biomaterials, Vol. 30, No. 20, pp. (3428-3435)

Christiaens, P., Vermeeren, V., Wenmackers, S., Daenen, M., Haenen, K., Nesladek, M., vandeVen, M., Ameloot, M., Michiels, L., \& Wagner, P. (2006). EDC-mediated DNA attachment to nanocrystalline CVD diamond films. Biosens.Bioelectron., Vol. 22, No. 2, pp. (170-177)

Fang, X., Tan, O. K., Tse, M. S., \& Ooi, E. E. (2010). A label-free immunosensor for diagnosis of Dengue infection with simple electrical measurements. Biosens.Bioelectron., Vol. 25, No. 5, pp. (1137-1142) 
Gorton, L. (Ed.). (2005). Comprehensive analytical chemistry: Biosensors and modern biospecific analytical techniques, Elsevier Science, 978-0444507150, Amsterdam

Grennan, K., Strachan, G., Porter, A. J., Killard, A. J., \& Smyth, M. R. (2003). Atrazine analysis using an amperometric immunosensor based on single-chain antibody fragments and regeneration-free multi-calibrant measurement. Anal.Chim.Acta, Vol. 500, No. 1-2, pp. (287-298)

$\mathrm{Gu}, \mathrm{H} ., \mathrm{Su}, \mathrm{X}$. , \& Loh, K. P. (2005). Electrochemical impedance sensing of DNA hybridization on conducting polymer film-modified diamond. J.Phys.Chem.B, Vol. 109, No. 28, pp. (13611-13618)

Harlow, E. \& Lane, D. (1999). Using Antibodies: A Laboratory Manual. Cold Spring Harbor Laboratory Press, 978-087969544-6, Cold Spring Harbor, NY

Joon-Hyung, J., Deng, Z., Alocilja, E. C., \& Grooms, D. L. (2008). Label-Free DNA Sensor on Nanoporous Silicon-Polypyrrole Chip for Monitoring Salmonella Species. Sensors Journal, IEEE, Vol. 8, No. 6, pp. (891-895)

Jung, Y., Kang, H. J., Lee, J. M., Jung, S. O., Yun, W. S., Chung, S. J., \& Chung, B. H. (2008). Controlled antibody immobilization onto immunoanalytical platforms by synthetic peptide. Anal.Biochem., Vol. 374, No. 1, pp. (99-105)

Koizumi, S., Kamo, M., Sato, Y., Ozaki, H., \& Inuzuka, T. (1997). Growth and characterization of phosphorous doped (111) homoepitaxial diamond thin films. Appl.Phys.Lett., Vol. 71, pp. (1065-1067)

Marrazza, G., Chianella, I., \& Mascini, M. (1999). Disposable DNA electrochemical sensor for hybridization detection. Biosens.Bioelectron., Vol. 14, No. 1, pp. (43-51)

Memming, R. (2000). Semiconductor electrochemistry. (1), Wiley-VCH, 978-3527301478, Weinheim

Micheli, L., Radoi, A., Guarrina, R., Massaud, R., Bala, C., Moscone, D., \& Palleschi, G. (2004). Disposable immunosensor for the determination of domoic acid in shellfish. Biosens.Bioelectron., Vol. 20, No. 2, pp. (190-196)

Nebel, C. E., Rezek, B., Shin, D., \& Watanabe, H. (2006). Surface electronic properties of Hterminated diamond in contact with adsorbates and electrolytes. Phys.Stat.Sol.(a), Vol. 203, No. 13, pp. (3273-3298)

Nebel, C. E., Shin, D., Rezek, B., Tokuda, N., Uetsuka, H., \& Watanabe, H. (2007). Diamond and biology. J.R.Soc.Interface, Vol. 4, No. 14, pp. (439-461)

Olowu, R. A., Arotiba, O., Mailu, S. N., Waryo, T. T., Baker, P., \& Iwuoha, E. (2010). Electrochemical Aptasensor for Endocrine Disrupting 17ß-Estradiol Based on a Poly(3,4-ethylenedioxylthiopene)-Gold Nanocomposite Platform. Sensors, Vol. 10, No. 11, pp. (9872-9890)

Pan, Y., Sonn, G. A., Sin, M. L., Mach, K. E., Shih, M. C., Gau, V., Wong, P. K., \& Liao, J. C. (2010). Electrochemical immunosensor detection of urinary lactoferrin in clinical samples for urinary tract infection diagnosis. Biosens.Bioelectron., Vol. 26, No. 2, pp. (649-654)

Popovtzer, R., Neufeld, T., Biran, D., Ron, E. Z., Rishpon, J., \& Shacham-Diamand, Y. (2005). Novel integrated electrochemical nano-biochip for toxicity detection in water. Nano.Lett., Vol. 5, No. 6, pp. (1023-1027)

Quershi, A., Saravan, K. S., Gurbuz, Y., Howell, M., Kang, W. P., \& Davidson, J. L. (2009). A new nanocrystalline diamond-based biosensor for the detection of cardiovascular risk markers, Proceedings of the Eurosensors XXIII conference, Lausanne, Switzerland, 2009 
Silin, V., V, Weetall, H., \& Vanderah, D. J. (1997). SPR Studies of the Nonspecific Adsorption Kinetics of Human IgG and BSA on Gold Surfaces Modified by Self-Assembled Monolayers (SAMs). J.Colloid Interface Sci., Vol. 185, No. 1, pp. (94-103)

Skládal, P. \& Kaláb, T. (1995). A multichannel immunochemical sensor for determination of 2,4-dichlorophenoxyacetic acid. Anal.Chim.Acta, Vol. 316, No. 1, pp. (73-78)

Smisdom, N., Smets, I., Williams, O. A., Daenen, M., Wenmackers, S., Haenen, K., Nesládek, M., D'Haen, J., Wagner, P., Rigo, J.-M., Ameloot, M., \& vandeVen, M. (2009). Chinese hamster ovary cell viability on hydrogen and oxygen terminated nanoand microcrystalline diamond surfaces. Phys.Stat.Sol.(a), Vol. 206, No. 9, pp. (20422047)

Tichoniuk, M., Ligaj, M., \& Filipiak, M. (2008). Application of DNA Hybridization Biosensor as a Screening Method for the Detection of Genetically Modified Food Components. Sensors, Vol. 8, No. 4, pp. (2118-2135)

Tran, D. T., Vermeeren, V., Grieten, L., Wenmackers, S., Wagner, P., Pollet, J., Janssen, K. P., Michiels, L., \& Lammertyn, J. (2011). Nanocrystalline diamond impedimetric aptasensor for the label-free detection of human IgE. Biosens.Bioelectron., Vol. 26, No. 6, pp. (2987-2993)

Ushizawa, K., Sato, Y., Mitsumori, T., Machinami, T., Ueda, T., \& Ando, T. (2002). Covalent immobilization of DNA on diamond and its verification by diffuse reflectance infrared spectroscopy. Chem.Phys.Lett., Vol. 351, pp. (105-108)

Vermeeren, V., Bijnens, N., Wenmackers, S., Daenen, M., Haenen, K., Williams, O. A., Ameloot, M., vandeVen, M., Wagner, P., \& Michiels, L. (2007). Towards a real-time, label-free, diamond-based DNA sensor. Langmuir, Vol. 23, No. 26, pp. (1319313202)

Vermeeren, V., Wenmackers, S., Daenen, M., Haenen, K., Williams, O. A., Ameloot, M., Vande, V. M., Wagner, P., \& Michiels, L. (2008). Topographical and functional characterization of the ssDNA probe layer generated through EDC-mediated covalent attachment to nanocrystalline diamond using fluorescence microscopy. Langmuir, Vol. 24, No. 16, pp. (9125-9134)

Wang, J., Firestone, M. A., Auciello, O., \& Carlisle, J. A. (2004). Functionalization of ultrananocrystalline diamond films by electrochemical reduction of aryldiazonium salts. Langmuir, Vol. 20, pp. (450-456)

Yang, W., Auciello, O., Butler, J. E., Cai, W., Carlisle, J. A., Gerbi, J. E., Gruen, D. M., Knickerbocker, T., Lasseter, T. L., Russell, J. N., Jr., Smith, L. M., \& Hamers, R. J. (2002). DNA-modified nanocrystalline diamond thin-films as stable, biologically active substrates. Nat.Mater., Vol. 1, No. 4, pp. (253-257)

Yang, W., Butler, J. E., Russell, J. N., Jr., \& Hamers, R. J. (2004). Interfacial electrical properties of DNA-modified diamond thin films: Intrinsic response and hybridization-induced field effects. Langmuir, Vol. 20, No. 16, pp. (6778-6787)

Yang, W., Butler, J. E., Russell, J. N., Jr., \& Hamers, R. J. (2007). Direct electrical detection of antigen-antibody binding on diamond and silicon substrates using electrical impedance spectroscopy. Analyst, Vol. 132, No. 4, pp. (296-306)

Young, H. D., Freedman, R. A., Sandin, T. R., \& Lewis Ford, A. (1999). University Physics. (10), Addison Wesley Publishing Company, 978-0201603224, Boston

Yuan, Y., Yuan, R., Chai, Y., Zhuo, Y., Liu, Z., Mao, L., Guan, S., \& Qian, X. (2010). A novel label-free electrochemical aptasensor for thrombin based on the nnano$\mathrm{Au} /$ thionine $\mathrm{n}$ multilayer films as redox probes. Anal.Chim.Acta, Vol. 668, No. 2, pp. (171-176) 


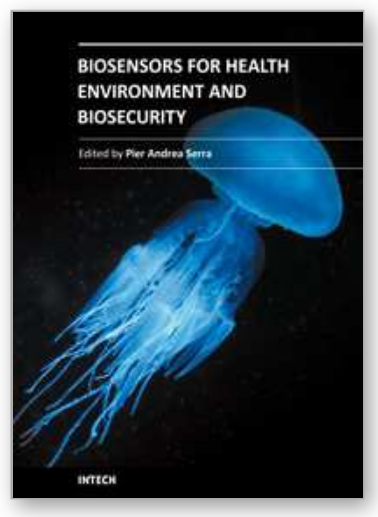

\author{
Biosensors for Health, Environment and Biosecurity \\ Edited by Prof. Pier Andrea Serra
}

ISBN 978-953-307-443-6

Hard cover, 540 pages

Publisher InTech

Published online 19, July, 2011

Published in print edition July, 2011

\begin{abstract}
A biosensor is a detecting device that combines a transducer with a biologically sensitive and selective component. Biosensors can measure compounds present in the environment, chemical processes, food and human body at low cost if compared with traditional analytical techniques. This book covers a wide range of aspects and issues related to biosensor technology, bringing together researchers from 16 different countries. The book consists of 24 chapters written by 76 authors and divided in three sections: Biosensors Technology and Materials, Biosensors for Health and Biosensors for Environment and Biosecurity.
\end{abstract}

\title{
How to reference
}

In order to correctly reference this scholarly work, feel free to copy and paste the following:

Veronique Vermeeren and Luc Michiels (2011). Evolution towards the implementation of point-of-care biosensors, Biosensors for Health, Environment and Biosecurity, Prof. Pier Andrea Serra (Ed.), ISBN: 978-953307-443-6, InTech, Available from: http://www.intechopen.com/books/biosensors-for-health-environment-andbiosecurity/evolution-towards-the-implementation-of-point-of-care-biosensors

\section{INTECH}

open science | open minds

\section{InTech Europe}

University Campus STeP Ri

Slavka Krautzeka 83/A

51000 Rijeka, Croatia

Phone: +385 (51) 770447

Fax: +385 (51) 686166

www.intechopen.com

\section{InTech China}

Unit 405, Office Block, Hotel Equatorial Shanghai

No.65, Yan An Road (West), Shanghai, 200040, China

中国上海市延安西路65号上海国际贵都大饭店办公楼 405 单元

Phone: +86-21-62489820

Fax: +86-21-62489821 
(C) 2011 The Author(s). Licensee IntechOpen. This chapter is distributed under the terms of the Creative Commons Attribution-NonCommercialShareAlike-3.0 License, which permits use, distribution and reproduction for non-commercial purposes, provided the original is properly cited and derivative works building on this content are distributed under the same license. 